\title{
RADIOTHERAPY WITH OR WITHOUT HYPERTHERMIA IN THE TREATMENT OF SUPERFICIAL LOCALIZED BREAST CANCER: RESULTS FROM FIVE RANDOMIZED CONTROLLED TRIALS
}

\author{
INTERNATIONAL COLLABORATIVE HYPERTHERMIA GROUP: \\ UK Medical Research Council: Clare C. Vernon, M.A., F.R.C.R., ${ }^{*}$ \\ JefFrey W. Hand, Ph.D., D.Sc., * Stanley B. Field, Ph.D.,** \\ David Machin, M.SC., Ph.D. ${ }^{\dagger}$ and Jill B. Whaley, B.V.M.\&S. ${ }^{\dagger}$
}
European Society for Hyperthermic Oncology and the Dutch Hyperthermia Group: Jacoba VAn der Zee, M.D., Ph.D., ${ }^{\ddagger}$ WIM L. J. van PutTen, M.Sc., ${ }^{\ddagger}$ Gerard C. van Rhoon, Ph.D., ${ }^{\ddagger}$ Jan D. P. van Dijk, Ph.D. ${ }^{\S}$ and Dionisio González GonZález, M.D., Ph.D. ${ }^{\S}$

\begin{abstract}
Princess Margaret Hospital/Ontario Cancer Institute: FeI-FeI Liu, M.D., F.R.C.P.C." Phyllis Goodman, M.Sc." ANd Michael Sherar, Ph.D."

*MRC Cyclotron Unit, Hammersmith Hospital, London, United Kingdom; ${ }^{\dagger}$ MRC Cancer Trials Office, Cambridge, United Kingdom; ${ }^{\ddagger}$ Departments of Hyperthermia and Statistics, Daniel den Hoed Cancer Center, Rotterdam, The Netherlands; ${ }^{8}$ Department of Radiotherapy, Academic Medical Center, Amsterdam,The Netherlands; "Departments of Radiation Oncology, Biostatistics, and Clinical Physics, Princess Margaret Hospital/Ontario Cancer Institute, University of Toronto, Canada
\end{abstract}

Purpose: Claims for the value of hyperthermia as an adjunct to radiotherapy in the treatment of cancer have mostly been based on small Phase I or II trials. To test the benefit of this form of treatment, randomized Phase III trials were needed.

Methods and Materials: Five randomized trials addressing this question were started between 1988 and 1991. In these trials, patients were eligible if they had advanced primary or recurrent breast cancer, and local radiotherapy was indicated in preference to surgery. In addition, heating of the lesions and treatment with a prescribed (re)irradiation schedule had to be feasible and informed consent was obtained. The primary endpoint of all trials was local complete response. Slow recruitment led to a decision to collaborate and combine the trial results in one analysis, and report them simultaneously in one publication. Interim analyses were carried out and the trials were closed to recruitment when a previously agreed statistically significant difference in complete response rate was observed in the two larger trials.

Results: We report on pretreatment characteristics, the treatments received, the local response observed, duration of response, time to local failure, distant progression and survival, and treatment toxicity of the 306 patients randomized. The overall CR rate for $\mathrm{RT}$ alone was $41 \%$ and for the combined treatment arm was $59 \%$, giving, after stratification by trial, an odds ratio of 2.3. Not all trials demonstrated an advantage for the combined treatment, although the $95 \%$ confidence intervals of the different trials all contain the pooled odds ratio. The greatest effect was observed in patients with recurrent lesions in previously irradiated areas, where further irradiation was limited to low doses.

Conclusion: The combined result of the five trials has demonstrated the efficacy of hyperthermia as an adjunct to radiotherapy for treatment of recurrent breast cancer. The implication of these encouraging results is that hyperthermia appears to have an important role in the clinical management of this disease, and there should be no doubt that further studies of the use of hyperthermia are warranted.

Breast cancer, Hyperthermia, Radiotherapy, Randomized trial.

Reprint requests to: Jill B. Whaley, MRC Cancer Trials Office, 5 Shaftesbury Road, Cambridge CB2 2BW UK
Accepted for publication 6 March 1996. 


\section{INTRODUCTION}

Early clinical applications of hyperthermia (HT) include those of Coley (5) and Westermark (34), whereas the origins of the use of $\mathrm{HT}$ as a radiosensitizing agent are to be found in the early years of the present century $(20,26)$. Although there was periodic interest through the intervening years, progress in the clinical application of HT was largcly frustrated by a lack of adequate techniques for heating tumors. Development of a biological rationale for the use of heat began during the $1960 \mathrm{~s}$ and, in recent years, the considerable effort applied to the physics and engineering problems associated with clinical HT has led to the development of acceptable techniques for treatment of superficial tumors (10). Sufficient knowledge has also been gained about methods of applying HT, with respect to fractionation and combination with other modalities, to result in a safe and possibly effective clinical treatment.

As a consequence, a large number of clinical Phase I and II studies $(11,15,24,27,32,33)$ have been carried out and their results indicate that HT may be of value in cancer treatment when given as an adjunct to either radiotherapy (RT) or chemotherapy. A few randomized clinical trials have also been performed $(9,25,31)$ but, in most of these, the numbers of patients recruited were too small or the lesions were not properly heated. It became clear that properly conducted prospectively randomized trials were needed to define the role of HT in cancer management. A trial in patients with malignant melanoma reported by $\mathrm{Ov}$ ergaard et al. in 1995 (21) was undertaken for the same reasons.

For patients with breast cancer, previous studies have indicated that local treatment does not affect survival in patients with recurrent disease, and that distant metastases will be detected ultimately in $75-93 \%$ of patients $(1,4$, 28). The median survival time for these patients ranges from 12-53 months, depending on tumor characteristics, and $21-50 \%$ will survive 5 years or longer (4). Local recurrence causes pain, bleeding, and ulceration in over $60 \%$ of patients (3), in addition to the psychological distress of watching a tumor grow. For both nonirradiated and previously irradiated recurrences, durable local control decreases with increasing size of the lesion and, for the latter group of patients, the radiation dose that can be administered safely is lower than that considered effective. Chemotherapy is also less effective in areas that have previously been irradiated. Thus, the use of a local treatment that can provide durable local tumor control for the remaining lifespan of these patients would be considered worthwhile.

The optimum HT regimen with regard to temperature or number of treatments is not known. However, a small number of HT fractions may be as effective as a larger number because of the development of thermotolerance (14). The need to select appropriate patients and tumors and the importance of compliance with appropriate quality assurance guidelines when delivering HT treatment has been highlighted by the results of previous clinical trials, especially Perez et al. (25).

The key question addressed by the randomized trials reported here was whether or not the addition of HT treatment to RT increased the complete response (CR) rate in patients suffering from recurrent or inoperable primary breast cancer.

\section{METHODS AND MATERIALS}

\section{Trial design}

The five randomized trials, with individual patient data combined in this analysis, were each planned independently with their own design, sample size requirements and, in some cases, stopping rules. All trials examined the effect of the addition of HT treatment to RT for treatment of breast cancer and the primary endpoint of each of the five trials was the local tumor response. The trials were performed by four collaborating groups: the Dutch Hyperthermia Group at the Academic Medical Center in Amsterdam and the Daniel den Hoed Cancer Center in Rotterdam (trial DHG), the Medical Research Council (MRC) hyperthermia group at the Hammersmith Hospital, London, UK, (trials MRC BrI and MRC BrR), the European Society of Hyperthermic Oncology (ESHO), (trial ESHO), and the hyperthermia group at the Princess Margaret Hospital/Ontario Cancer Institute, Toronto, Canada (trial PMH). The groups in Rotterdam and London coordinated multicenter trials.

At the design stage of each trial, sample sizes were calculated on the basis of the anticipated CR rate to $R T$ alone and the anticipated increased response rates, $\delta$, for RT + HT together with test size $\alpha=0.05$ and power $1-\beta=0.8$ (18). The basis of these calculations is summarised for the individual trials in Table 1 together with the corresponding recruitment targets.

The decision to combine the information from the ESHO and two MRC trials was made in October 1990, because it had become clear that the accrual rate of the separate trials was too low to reach their individual design targets. In particular, without the prospect of combining the results, the MRC trials would have been closed to recruitment, leaving, at best, considerable uncertainty about the real effect of HT. Given the similarities in design of the ESHO and MRC trials, it was possible to plan to combine prospectively the analysis of these three trials without altering the design or data management procedures of the individual trials. The MRC trials had included a third group, within the same protocol, of patients with head and neck nodes, which recruited only 9 patients and which was closed at the time of the decision to combine with the ESHO group. These patients are not included in this report. Just prior to this stage, following an interim analysis and a review of more recent literature, the required number of patients was recalculated for the MRC trials, assuming a two-tailed test size and power, but an odds ratio (OR) for obtaining a local CR equal to 2 , corresponding 
Table 1. Anticipated complete response (CR) rates to radiotherapy (RT), anticipated benefit by the addition of hyperthermia (HT), planned trial size, date of opening, and final patient accrual

\begin{tabular}{|c|c|c|c|c|c|c|c|c|}
\hline \multirow[b]{2}{*}{ Trial } & \multicolumn{2}{|c|}{ Anticipated CR \% } & \multirow{2}{*}{$\begin{array}{c}\text { Anticipated } \\
\text { benefit } \delta \\
(\%)\end{array}$} & \multirow{2}{*}{$\begin{array}{l}\text { Odds } \\
\text { ratio }\end{array}$} & \multirow{2}{*}{$\begin{array}{c}\text { Total } \\
\text { planned }\end{array}$} & \multirow{2}{*}{$\begin{array}{c}\text { Date trial } \\
\text { opened }\end{array}$} & \multicolumn{2}{|c|}{ Final accrual } \\
\hline & RT & $\mathrm{RT}+\mathrm{HT}$ & & & & & RT & $\mathrm{RT}+\mathrm{IIT}$ \\
\hline DHG & 30 & 60 & $30^{*}$ & 3.5 & 80 & May '88 & 19 & 19 \\
\hline $\begin{array}{l}\text { MRC BrI } \\
\text { MRC BrR }\end{array}$ & 45 & 55 & $10^{\dagger}$ & 1.5 & $800^{\ddagger}$ & Jan '89 & 71 & 108 \\
\hline $\begin{array}{l}\text { ESHO } \\
\text { PMH }\end{array}$ & $\begin{array}{l}20-60 \\
35-50\end{array}$ & $\begin{array}{l}40-80 \\
55-75\end{array}$ & $\begin{array}{l}20^{*} \\
20^{+}\end{array}$ & $\begin{array}{l}2.25 \\
2.5\end{array}$ & $\begin{array}{l}152 \\
234\end{array}$ & $\begin{array}{l}\text { Oct '89 } \\
\text { July '91 }\end{array}$ & $\begin{array}{l}29 \\
16\end{array}$ & $\begin{array}{l}27 \\
17\end{array}$ \\
\hline Total & & & & & 1266 & & 135 & 171 \\
\hline
\end{tabular}

* One-sided $\alpha=0.05$

${ }^{\dagger}$ Two-sided $\alpha=0.05$.

${ }_{\ddagger}$ Originally planned sample size 800 for all MRC trials combined, with a $60: 40$ randomization in favor of the HT arm.

Recalculation in September 1990 following an interim analysis based on the first 67 patients, assuming a larger treatment effect $(\delta$ $=17 \%$ ), led to a reduced target recruitment of 280 .

to a difference in CR rates of $\delta=17 \%$. This gave a revised target recruitment of 280 patients. After including the ESHO trial, this target was retained for the combined analysis. Subsequently, the opportunity arose to include the DHG and PMH trials within the collaboration in 1992, retaining the combined recruitment target of 280 . For purposes of this report, the trials are ordered in the sequence of the dates that the trial was opened (Table 1).

\section{Patient eligibility criteria}

The common eligibility criteria of the five trials included measurable breast cancer lesions where local therapy was indicated and surgery was not feasible. In addition, treatment with a prescribed (re)irradiation schedule and HT according to the ESHO or Radiation Therapy Oncology Group (RTOG) guidelines $(8,12)$ were both feasible, and informed consent was obtained. In the MRC trials, patients were included if they were already on chemotherapeutic or hormone treatment, provided that their cancers were progressing locally. In the DHG, ESHO, and PMH trials, those on systemic chemotherapy were not eligible but patients already on hormonal treatment were, if their local disease had progressed and required local intervention.

Trial specific details are:

\section{(a) DHG}

Patients with breast cancer recurrences in previously irradiated areas, patients with recurrences in nonirradiated areas, for whom shortened fractionation schedules were considered appropriate in view of poor performance status or long traveling distances, and others with inoperable recurrences in previously nonirradiated areas who were considered fit for a high dose fractionated radiation schedule. After the ESHO trial had been opened, patients with recurrences in previously irradiated areas were entered into the ESHO trial. (b) MRC BrI

Patients with primary advanced (T3 or T4) disease that was deemed inoperable (13).

(c) MRC BrR

Patients with recurrent disease, with or without previous irradiation.

(d) ESHO

Patients with recurrent disease within a previously irradiated area.

(e) PMH

Patients with postmastectomy recurrences with or without previous irradiation.

Thus, within the combined trials, three groups of patients can be distinguished. These are patients with untreated primary inoperable breast cancer, those with recurrent tumors in sites that had no previous irradiation, and those with recurrences in previously irradiated areas.

\section{Disease assessment}

Lesions were measured at entry to the trials and were classified as single or multiple, depending on whether or not there was more than one discrete area of tumor within the intended treatment area. The area of a single tumor was calculated as the product of the maximum diameter of the lesion and its perpendicular diameter. The area of multiple disease was the product of the maximum length and width of the area of disease to be treated. The depth was defined as the maximum tumor depth in the treatment area. The majority of these and subsequent measurements were verified independently by personnel other than the clinical coordinators.

The presence or history of metastatic disease at the time of randomization was also recorded, although PMH was the only trial to conduct comprehensive staging prior to entry.

\section{Randomization}

In all trials, randomization was conducted by telephone call to a central office. In the DHG trial, stratification was 
by participating center, whether or not previous RT had been given, and the preferred RT schedule. The two MRC studies were randomized, $40 \%$ to radiation only and $60 \%$ to the combined treatment, to provide more information on thermal parameters, which will be reported elsewhere. In the other trials, $50 \%$ of patients were allocated to each treatment arm. In the ESHO trial, stratification was by participating center and the diameter of the lesions ( $\leq$ or $>3 \mathrm{~cm}$ ). In the PMH trial, patients were stratified according to whether or not previous RT had been administered, area of disease ( $\leq$ or $>25 \mathrm{~cm}^{2}$ ), and tumor depth ( $\leq$ or $>1 \mathrm{~cm}$ ).

In the ESHO and DHG trials, multiple lesions of one patient could be separately randomized and evaluated. However, for the purposes of this report, only one lesion per patient, the first randomized, is included.

\section{Radiotherapy and hyperthermia schedules}

Radiation was applied using either high voltage photons or electrons through one or multiple ports. Within the DHG, MRC BrR, and PMH trial protocols, radical and palliative schedules of RT were defined. Radical treatments were used where tumors occurred in areas that had not received previous radiation therapy. Palliative treatment was used for recurrences in previously treated areas. Details of radiation doses used in each trial are given in Table 2; the doses administered were the same, regardless of the outcome of randomization.

To compare the various RT treatments given by the different groups, "effective doses" have been computed for each of the treatments, based on the linear quadratic formula with $\alpha / \beta$ taken as 10 and the correction for repopulation based on 0.5 Gy per day, for a fraction size of 2 Gy. These values have been converted to equivalent RT doses as given in 30 fractions over 6 weeks. The relationship between these doses is not very sensitive to the choice of value for $\alpha / \beta$. The topic has been thoroughly reviewed by Steel (30).

Hyperthermia treatments were given in accordance with quality assurance guidelines drawn up under the auspices of ESHO (12) or, in the case of PMH, RTOG (8). For HT treatment to be administered, patients were positioned on a couch. Thermometry probes were inserted into catheters that had been introduced into the tumorous area under local anesthesia and, also, placed on the tumor surface and on normal skin. Hyperthermia was induced using various externally applied electromagnetic applicators, most of which operated at $434 \mathrm{MHz}$. Current sheet applicators were used at Hammersmith, and water-fillcd waveguides in Amsterdam, Rotterdam, and Latina, Italy. In addition, dielectrically loaded waveguide applicators were used in Utrecht (custom-built), Trento', Warsaw ', Graz', Cambridge $^{1}$, and Saarbrucken ${ }^{2}$. Warsaw and PMH used commercial dielectrically loaded waveguide applicators ${ }^{1}$, op- erating at $915 \mathrm{MHz}$. The only $\mathrm{HT}$ treatment given at Sheffield involved a custom-built mechanically scanned $2450 \mathrm{MHz}$ air-filled waveguide. Except for this single treatment using the air-filled waveguide applicator, all treatments involved the use of a temperature-controlled water bolus that was either contained in a flexible bag or was an integral part of the applicator.

In the DHG, MRC, and ESHO trials, the aim of each HT treatment was to achieve a minimum temperature of $43^{\circ} \mathrm{C}$ at all sensors located within the tumor and to maintain this for a period of $60 \mathrm{~min}$. The hyperthermal treatment was considered to commence either $10 \mathrm{~min}$ after the electromagnetic fields were applied or from the time at which all sensors within the tumor recorded at least $43^{\circ} \mathrm{C}$ (if this was less than $10 \mathrm{~min}$ ), and to finish $60 \mathrm{~min}$ later. In the DHG trial, the total treatment time was $60 \mathrm{~min}$. In the PMH trial, the intention was to reach a minimum temperature of $42.5^{\circ} \mathrm{C}$ at monitored locations in the tumor within $15 \mathrm{~min}$ and to maintain this for $30 \mathrm{~min}$.

Three measures of the actual HT treatments delivered were calculated for the MRC and PMH trials, and the treatments conducted in Rotterdam for the ESHO and DHG trials. These were the lower 90th percentile of all intratumor temperatures recorded during a treatment $\left(T_{90}\right)$, the 50th percentile of all intratumor temperatures recorded during a treatment $\left(T_{50}\right)$, and the maximum intratumor temperature recorded during a treatment $\left(\mathrm{Tmax}_{\max }\right)$. Temperatures were recorded every $20 \mathrm{~s}$ at all sensors during the duration of treatment. In contrast to the other trials, in which stationary multisensor temperature probes were used, the PMH trial employed a thermal mapping technique with generally two intratumoral sensors scanning 5 mm continuously, through target volume, plus six surface sensors.

\section{Endpoints}

Local response. Local response was assessed according to the WHO criteria of objective response in measurable disease (35). Complete response of the treated area required confirmation by a second consecutive observation at least 4 weeks after the first. Following this confirmation, the date of the CR was defined as the date of the first observation without evidence of tumor within the treatment area.

Patients who either received no treatment or who died before response could be evaluated were classified as treatment failures (no CR). Death without a previously confirmed CR counted as a failure. Patients who achieved local complete regression only after the addition of a (new) systemic therapy were also classified as failures.

Progressive disease was defined as a $25 \%$ increase in the size of measured lesions, or the appearance of new lesions within the treated area. Local progression was also deemed to have occurred if additional local treatment had 
Table 2. Treatment schedules and effective radiation doses for (re)irradiation plus hyperthermia in the 5 trials

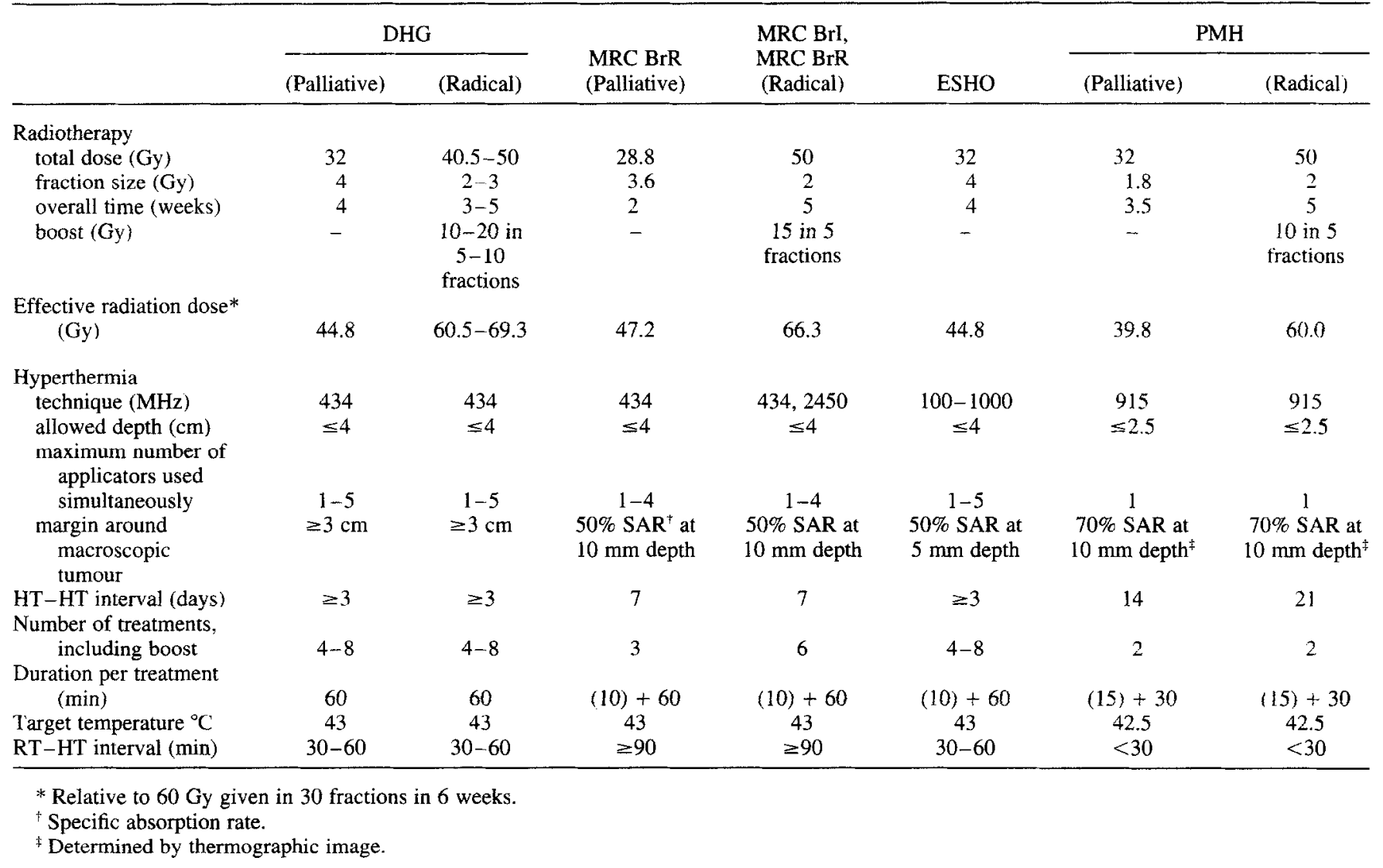

been given, whether or not a CR had previously been obtained.

Time to local failure and distant progression. For patients not reaching a $C R$, the time to local failure was set at zero, even if the patient initially showed a partial response or stable disease. For patients with a CR, time to local failure was the time to local progression from the date of randomization. Patients dying in local CR, or in continuing local $\mathrm{CR}$ at last follow-up, were censored at the date of death or last follow-up.

The time to development of distant metastatic disease was recorded.

Survival. Overall survival was calculated from the date of randomization to death or was censored at the date last known to be alive.

Side effects. Acute and late toxicities for both RT and HT treatments were documented. Tolerance and patient acceptability of the treatments were also recorded for the MRC trials by means of a self-reported questionnaire completed by the patients. A quality of life study was also conducted at PMH.

Data management. A common data set was defined for the combined interim and final analyses, although this underwent some revision toward the end of the trials. These data were abstracted from the data files of the individual trials. All data were sent to Rotterdam, the statistical center for the ESHO and DHG trials, for merging and analysis. Data management of the DHG and ESHO trials used
dBase III plus. COMPACT was used for data management of the MRC trials (6). For the PMH trial, the SAS database package was used. For analysis of the data, the statistical package STATA (29) was used. In COMPACT, a module was developed to export data into STATA format.

Interim analysis and data monitoring. After the decision to combine the trials had been made, with a combined recruitment target of 280 patients, subsequent interim analyses were planned once a year, with emphasis on the monitoring of the trials, in particular, the accrual. A formal stopping rule based on the interim results of the combined data was not defined, because this could interfere with the design objectives of the individual trials. However, the following pragmatic guideline based on the intention to treat principle was adopted (17):

"At interim analyses tests of differences would be performed for each trial on an annual basis. The results would not be disclosed to participants unless both the ESHO trial and the MRC BrR trial showed a statistically significant difference (two-sided test) in the CR rate between treatments with $p<0.05$ and the combined analysis of all trials would be statistically significant with $p<0.001$."

On this basis, the decision to stop or continue each trial was left to the specific coordinating committee.

Statistical analysis. Logistic regression stratified by trial was used for the evaluation of the differences between treatments in CR rate and for the calculation of ORs and associated $95 \%$ confidence intervals $(\mathrm{CI})$, an $\mathrm{OR}<1$ in- 
dicating a benefit of the addition of HT (2, page 269). The sizes of the boxes in Fig. 1 are proportional to the standard error of $\log \mathrm{OR}$, and give an indication of the relative precision of the estimate of the OR for each trial. Time to local failure and survival were analysed using KaplanMeier curves, the logrank test and the Cox proportional hazards model. For these analyses, the relative efficacy of the two treatments was assessed by the hazard ratio (HR) and the associated 95\% CIs, a HR $<1$ indicating a benefit from the addition of HT (22).

\section{RESULTS}

There were 317 lesions randomized in 307 patients. Of these, one patient was excluded because she had microscopic nonmeasurable disease and, therefore, had been randomized in error. She was treated with RT only, according to randomization, and maintained local control to the time of this analysis 5 years later. Ten secondary lesions are not included in the analysis. Eight of these were from patients with multiple lesions that were separately randomized at entry to the trials, and two were MRC BrR patients who had previously been entered into MRC BrI. Of these 10 lesions, 7 were randomized to combined therapy, of which 3 achieved CR and, of these, none relapsed locally. Two patients were still alive after 3 years. Of the 3 randomized to RT only, none achieved CR.

The remainder of this report refers to the remaining 306 lesions in 306 patients.

Following interim analyses in 1991 and 1992, the third interim analysis, carried out in July 1993, fulfilled the cri- teria for disclosure and, at the same time, recruitment had reached 269 patients, nearing the target number of 280 . At a meeting of all the participants concemed, it was decided to continue accrual until the end of 1993, and then close the trials.

The final analysis was conducted in June 1994, ensuring a minimum follow-up of 5 months for all patients.

\section{Patient characteristics}

The pretreatment characteristics including age, disease status, previous irradiation, systemic therapy prior to randomization, presence or history of distant metastases, 10cation, size and extent of the lesions of the 306 patients recruited are summarized in Table 3 . There are some clear differences between trials that reflect the different eligibility criteria within the respective protocols. For example, patients with chest wall and multiple lesions are included in all trials except MRC BrI, and nodal disease was treated in all except the MRC trials.

In 152 patients (50\%), there was no evidence or history of distant disease but, as already indicated, comprehensive staging prior to randomization was only carried out for the PMH patients. Two hundred and sixteen $(71 \%)$ lesions were on the chest wall and $79(26 \%)$ in breast tissue. One hundred and fifty-nine (52\%) patients had single lesions. One patient in the MRC BrR trial was male and received RT only.

In the combined treatment arm, there was a higher proportion of patients who had received chemotherapy prior to randomization and the median lesion size was greater. There appears to be no obvious explanation other than

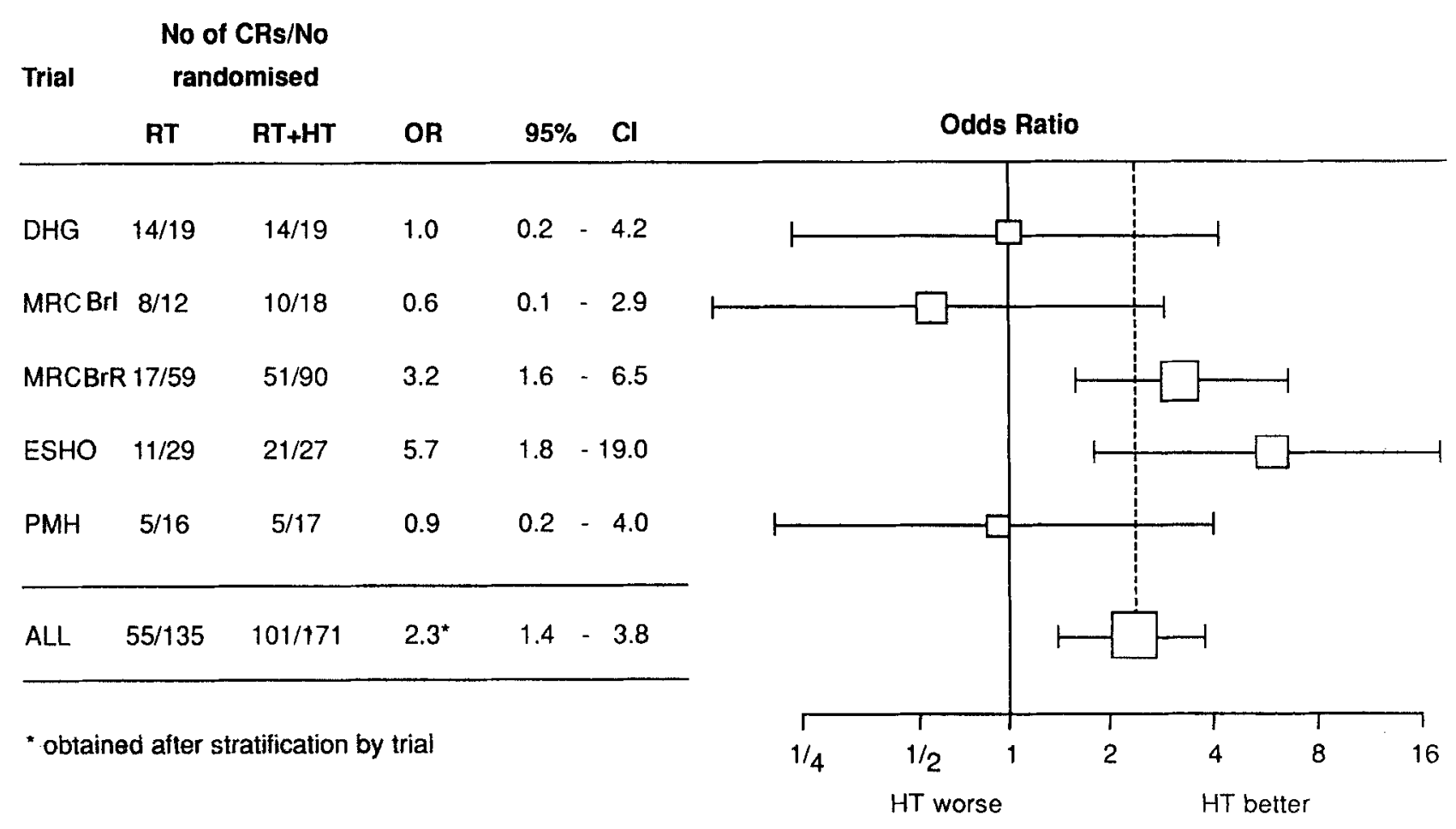

Fig. 1. The $\mathrm{OR}$ for a $\mathrm{CR}$ by trial, with associated $95 \%$ confidence intervals. 
Hyperthermia for breast cancer - InTERnATIONAL COLlaboRATIVE HYPERTHERMia Group

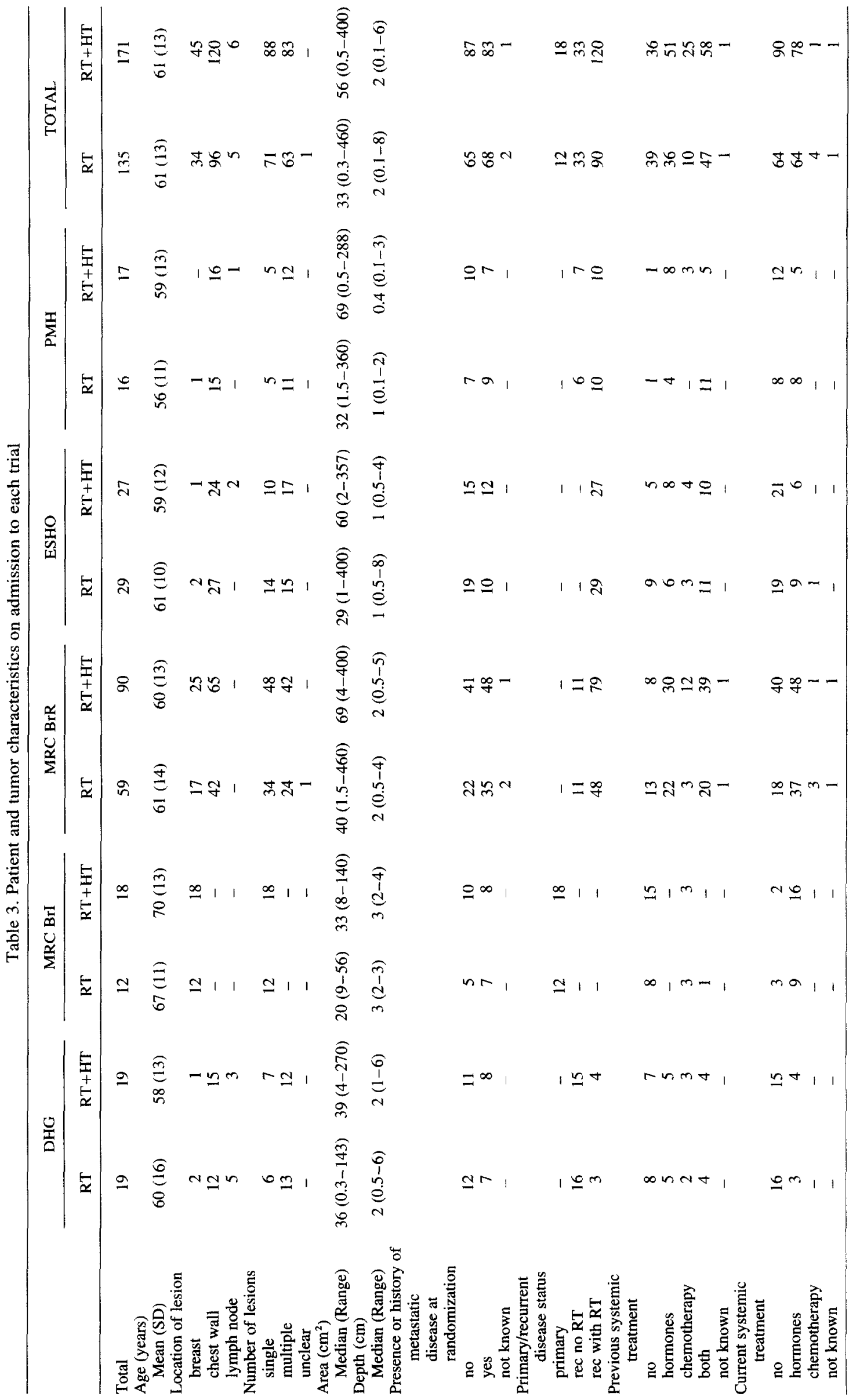


chance for these imbalances, but they are adjusted for in the analysis presented below.

\section{Treatment received}

Ninety-five percent of patients received the treatment to which they were randomized. Details of the treatments administered are summarized in Tables 4 and 5 .

There were 11 patients ( 5 randomized to RT and 6 to $\mathrm{RT}+\mathrm{HT}$ ) who received no treatment because of disease progression. One patient allocated to RT only refused treatment and one allocated to RT only received combined treatment (five sessions of HT). The majority of patients received palliative doses of RT because they had been previously radically irradiated, although the ESHO trial was the only one in which all patients had been previously irradiated.

Although the intention in all HT treatments was to raise intratumor temperatures to a minimum of $43^{\circ} \mathrm{C}\left(42.5^{\circ} \mathrm{C}\right.$ in the case of $\mathrm{PMH}$ ), this target was not achieved in the majority of treatments. The results of an analysis of the actual temperatures achieved, in terms of three thermal parameters previously shown to be reasonable descriptors of HT treatment (7), are given in Table 5. In general, the duration of treatments actually delivered was similar to that intended (sec Table 2).

\section{Local response}

The number of patients and CRs by trial and treatment group are given in Table 6, together with the median time to CR and details of disease progression and survival.

Fifty-five of the 135 patients randomized to RT alone $(41 \%)$ and 101 of the 171 of the patients randomized to
RT + HT (59\%) had a CR. This difference, following logistic regression analysis stratified by trial, is statistically significant with $p<0.001$, and translates into an $\mathrm{OR}_{\text {stratified }}=2.3(95 \% \mathrm{CI} 1.4$ to 3.8$)$. However, as is shown in Table 6, there is considerable variation in the CR rates, and the corresponding ORs, observed in the five trials. As we have already indicated, the two largest studies (ESHO and MRC BrR) both show a statistically significant ( $p=$ 0.004 and 0.001 , respectively) advantage for the addition of HT, whereas the other three trials do not show a benefit (ORs < 1). Such variation in the ORs may be explained by the small patient numbers in these trials, because a formal test for interaction indicates that there is not a statistically significant difference in HT effect among the 5 trials $(p=0.14)$. Even though the individual trial results differ, they are not inconsistent with an advantage for HT, as is indicated by Fig. 1.

Univariate analysis of the effect of baseline characteristics on the CR rate showed that it depended strongly on the size of the tumor (CR rate $70 \%$ for lesions with area $<16 \mathrm{~cm}^{2}$ compared to $45 \%$ for lesions with area $\geq 16$ $\mathrm{cm}^{2}$ ), the depth of the lesion (CR rate $60 \%$ for lesions with a depth $<3 \mathrm{~cm}$, vs. $38 \%$ for lesions with depth $\geq 3$ $\mathrm{cm}$ ), and on a history or presence of metastatic disease outside the treatment area (CR rate $39 \%$ vs. $63 \%$ ). This last effect is caused by the higher death rate of patients with a history of metastatic disease. These patients had a higher risk of dying from progression elsewhere, and the tumor in the treated area had not yet had the time to disappear completely. In the multiple logistic regression analysis, stratified by trial and adjusted for the baseline characteristics that were individually prognostic for CR (maximum diameter, area of lesions, and systemic disease), the benefit of the addition of HT to RT was con-

Table 4. Summary of radiotherapy treatment received in each trial

\begin{tabular}{|c|c|c|c|c|c|c|}
\hline & DHG & MRC BrI & MRC BrR & ESHO & PMH & Total \\
\hline Total & 38 & 30 & 149 & 56 & 33 & 306 \\
\hline \multicolumn{7}{|c|}{ Treatment deviations } \\
\hline No treatment & - & - & 4 & 1 & - & 5 \\
\hline $\mathrm{RT}+\mathrm{HT}$ & - & - & 1 & - & - & 1 \\
\hline \multicolumn{7}{|l|}{ Allocated RT + HT } \\
\hline No treatment & 1 & 1 & 3 & 1 & - & 6 \\
\hline \multicolumn{7}{|c|}{ Radiotherapy, total dose (Gy) (actual) } \\
\hline No RT & 1 & 1 & 7 & 2 & - & 11 \\
\hline$<28$ & 1 & 1 & 9 & 2 & 1 & 14 \\
\hline $28-32$ & 11 & - & 105 & 52 & 19 & 187 \\
\hline $33-40$ & - & 2 & 14 & - & - & 16 \\
\hline $41-50$ & 1 & 3 & 6 & - & - & 10 \\
\hline $51-60$ & 6 & 9 & 6 & - & 13 & 34 \\
\hline $61-70$ & 18 & 14 & 2 & - & - & 34 \\
\hline \multicolumn{7}{|c|}{$\begin{array}{l}\text { Dose in relation to previous RT:Mean } \\
\text { (SD) }\end{array}$} \\
\hline primary & - & $58(12)$ & - & - & & $58(12)$ \\
\hline recurrent no RT & $59(15)$ & - & $47(12)$ & - & $58(8)$ & $55(14)$ \\
\hline recurrent RT & $31(3)$ & - & $29(2)$ & $31(3)$ & $33(8)$ & $30(4)$ \\
\hline
\end{tabular}


Table 5. Summary of hyperthermia treatment received in each trial

\begin{tabular}{|c|c|c|c|c|c|c|}
\hline & DHG & MRC BrI & MRC BrR & ESHO & PMH & Total \\
\hline \multicolumn{7}{|c|}{$\begin{array}{l}\text { Hyperthermia, (number of } \\
\text { treatments) }\end{array}$} \\
\hline 0 & 1 & 1 & 3 & 1 & - & 6 \\
\hline 1 & - & - & 2 & - & - & 2 \\
\hline 2 & - & - & 5 & _- & 17 & 22 \\
\hline 3 & 1 & 1 & 73 & 1 & - & 76 \\
\hline 4 & 1 & 4 & 4 & - & - & 9 \\
\hline 5 & 9 & 1 & $3^{*}$ & 5 & - & 18 \\
\hline 6 & 1 & 11 & - & 1 & - & 13 \\
\hline 8 & 6 & - & - & 19 & - & 25 \\
\hline \multicolumn{7}{|l|}{$\begin{array}{l}\text { Thermal parameters, } \\
\text { median (range) }\end{array}$} \\
\hline $\mathrm{T}_{90}\left({ }^{\circ} \mathrm{C}\right)$ & $39.0(35.7-41.1)$ & $40.4(37.6-42.7)$ & $40.7(34.6-43.3)$ & $39.5(37.6-41.5)$ & $40.7(39.5-43.0)$ & \\
\hline $\mathrm{T}_{50}\left({ }^{\circ} \mathrm{C}\right)$ & $40.7(39.3-42.2)$ & $42.3(39.2-44.4)$ & $42.5(40.2-44.7)$ & $41.1(38.5-42.9)$ & $42.2(41.0-43.6)$ & \\
\hline $\operatorname{Tmax}_{\max }\left({ }^{\circ} \mathrm{C}\right)$ & $43.5(41.9-50.7)$ & $45.1(41.0-47.5)$ & $45.6(42.0-49.1)$ & $43.3(39.8-44.7)$ & $44.6(43.4-46.5)$ & \\
\hline $\begin{array}{l}\text { Duration of each } \\
\text { treatment (min), } \\
\text { median (range) }\end{array}$ & $60(55-61)$ & $60(30-60)$ & $60(17-65)$ & $60(60-60)$ & $28(22-36)$ & \\
\hline $\begin{array}{l}\text { No of intra-tumor } \\
\text { sensors, median } \\
\text { (range) }\end{array}$ & $7(4-13)$ & $10(4-20)$ & $10(3-36)$ & $6(0-11)$ & $28(7-52)^{\ddagger}$ & \\
\hline
\end{tabular}

* In addition, one patient allocated RT received RT plus $5 \mathrm{HT}$ treatments.

${ }^{\dagger}$ Thermal parameters for Rotterdam patients only.

Thermal mapping.

firmed and enhanced, $\mathrm{OR}_{\text {Adjusted }}=3.0,95 \% \mathrm{CI} 1.7$ to 5.1 $(p=0.0001)$.

Primary lesions, or recurrent lesions in an area not previously irradiated, had a higher CR rate $(61 \%)$ than recurrent lesions in a previously irradiated area $(46 \%)$. Lesions in an area exposed to previous radiation received palliative doses of radiation around $28 \mathrm{~Gy}$, and most of the lesions $(80 \%)$ in areas without previous radiation received radical treatment with doses over $40 \mathrm{~Gy}$.

Even though the differences in treatment effects between the studies are not inconsistent with an overall benefit of HT, as measured by a combined OR, the differences could be caused by clinically relevant differences in patient characteristics and, associated with this, in radiation

Table 6. Percentage of $\mathrm{CR}$, median time to $\mathrm{CR}$, disease progression, and survival, by trial and treatment

\begin{tabular}{|c|c|c|c|c|c|c|c|c|c|c|c|c|}
\hline & \multicolumn{2}{|c|}{ DHG } & \multicolumn{2}{|c|}{ MRC BrI } & \multicolumn{2}{|c|}{ MRC BrR } & \multicolumn{2}{|c|}{ ESHO } & \multicolumn{2}{|c|}{ PMH } & \multicolumn{2}{|c|}{ TOTAL } \\
\hline & RT & $\mathrm{RT}+\mathrm{HT}$ & RT & $\mathrm{RT}+\mathrm{HT}$ & $\mathrm{RT}$ & $\mathrm{RT}+\mathrm{HT}$ & RT & $\mathrm{RT}+\mathrm{HT}$ & RT & $\mathrm{RT}+\mathrm{HT}$ & RT & $\mathrm{RT}+\mathrm{HT}$ \\
\hline Total & 19 & 19 & 12 & 18 & 59 & 90 & 29 & 27 & 16 & 17 & 135 & 171 \\
\hline CR & 14 & 14 & 8 & 10 & 17 & 51 & 11 & 2 & 5 & & 55 & 101 \\
\hline$\%$ & 74 & 74 & 67 & 56 & 29 & 57 & 38 & 78 & 31 & 29 & 41 & 59 \\
\hline Difference & \multirow{2}{*}{\multicolumn{2}{|c|}{$\begin{array}{l}0 \\
1.00\end{array}$}} & \multirow{2}{*}{\multicolumn{2}{|c|}{$\begin{array}{c}-11 \\
0.65\end{array}$}} & \multirow{2}{*}{\multicolumn{2}{|c|}{$\begin{array}{l}28 \\
3.23\end{array}$}} & \multirow{2}{*}{\multicolumn{2}{|c|}{$\begin{array}{l}40 \\
5.73\end{array}$}} & \multirow{2}{*}{\multicolumn{2}{|c|}{$\begin{array}{l}-2 \\
0.92\end{array}$}} & \multirow{2}{*}{\multicolumn{2}{|c|}{$\begin{array}{l}18 \\
2.30 *\end{array}$}} \\
\hline $\mathrm{OR}$ & & & & & & & & & & & & \\
\hline $\begin{array}{l}\text { Median time to CR } \\
\text { (days) } \\
\text { Local recurrence after }\end{array}$ & 105 & 77 & 399 & 149 & 84 & 77 & 90 & 70 & 127 & 91 & 101 & 81 \\
\hline CR & 6 & 3 & - & 1 & 6 & 3 & 4 & 8 & 1 & 2 & 17 & 17 \\
\hline Progres & 9 & 11 & 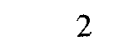 & 3 & 12 & 42 & 7 & 1 & 1 & 1 & 31 & 75 \\
\hline Dead & 2 & 6 & 2 & 4 & 9 & 36 & 3 & 6 & - & - & 16 & 52 \\
\hline No CR & 5 & 5 & 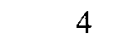 & 8 & 42 & 39 & 18 & 8 & 11 & 12 & 80 & 70 \\
\hline Progression elsewhere & 5 & 3 & 4 & 5 & 33 & 31 & 14 & 5 & 10 & 11 & 66 & 55 \\
\hline Dead & 4 & 3 & 4 & 5 & 35 & 36 & 9 & 4 & 6 & 6 & 58 & 54 \\
\hline $\begin{array}{l}\text { All Patients, } \% \\
\text { Actuarial survival } \\
\text { at } 2 \text { year (SE) }\end{array}$ & $65(12)$ & $62(13)$ & $48(15)$ & $44(12)$ & $32(6)$ & $21(5)$ & $42(11)$ & $68(10)$ & $46(17)$ & $59(13)$ & $41(5)$ & $36(4)$ \\
\hline
\end{tabular}

* Estimated using logistic regression stratified by trial. 


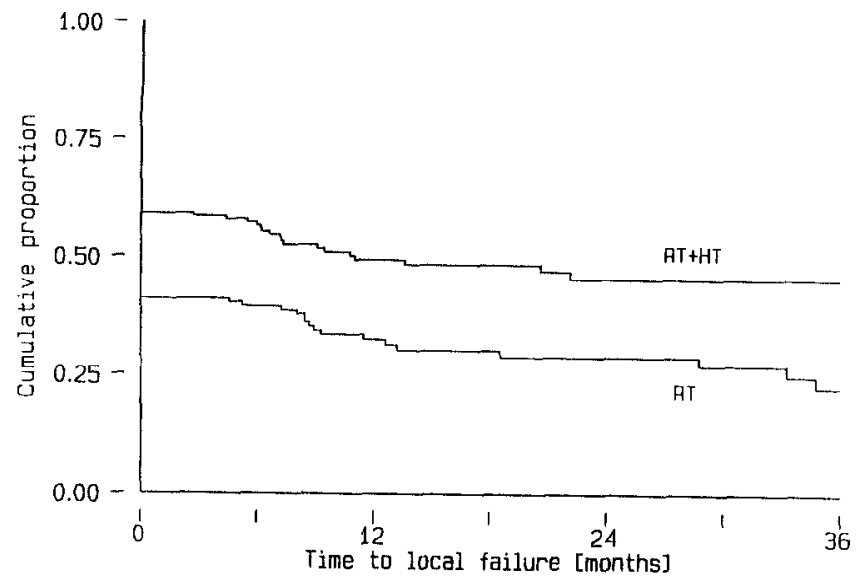

Fig. 2. Local failure-free curves by arm; pooled

treatment characteristics between the studies. Therefore, interactions between the HT treatment effect and the above-mentioned prognostic factors were studied. No significant difference in treatment effect between small lesions $\left(<16 \mathrm{~cm}^{2}\right)$ and large lesions $\left(\geq 16 \mathrm{~cm}^{2}\right)$ was found $(p=0.41)$. The HT effect was somewhat less with deeper tumors, but this was far from statistically significant $(p=$ 0.21 ). Also, the presence or a history of metastatic disease was not related to the HT effect $(p=0.70)$. There was, however, a clear interaction between palliative and radical $\mathrm{RT}$ in terms of HT effect $(p<0.01)$. In the group of patients with lesions in areas not previously irradiated, generally treated with radical $\mathrm{RT}$, no difference in $\mathrm{CR}$ rate was found between those in the RT arm $(n=45, \mathrm{CR}=$ $60 \%)$ and those in the combined treatment arm $(n=51$, $\mathrm{CR}=63 \%)$, with an $\mathrm{OR}=1.24(95 \% \mathrm{CI} 0.46,3.32)$. In the group of patients with lesions in previously irradiated areas, treated with palliative RT doses, the CR rate in the combined treatment arm was much higher $(n=120, \mathrm{CR}$ $=57 \%)$ than in the RT only arm $(n=90, \mathrm{CR}=31 \%)$. The corresponding OR in this subgroup is 4.7 (95\% CI 2.4-9.5).

The median time to response was shorter by approximately 3 weeks for patients subjected to the combined treatment, as opposed to RT alone, (Table 6), although the magnitude of this difference varied from trial to trial.

\section{Duration of response}

All patients who did not reach a $\mathrm{CR}$ were considered to be local failures. Of the patients who achieved a CR, $17 \%$ of those receiving RT $+\mathrm{HT}$, and $31 \%$ of the RT only patients had a local relapse during follow-up. Figure 2 shows the actuarial local relapse-free survival for the two treatment arms pooled over the trials. Patients who did not reach a CR were considered failures on the day of randomization. After that day, failures are patients with local relapse. Patients who did not relapse were censored either at death or at the time of last follow-up, as appropriate. These curves show that the advantage of HT is maintained during follow-up. A Cox regression analysis gave a HR, for RT + HT compared to RT alone, of 0.67 $(p=0.007,95 \%$ Cl $0.5-0.89)$.

\section{Distant progression and survival}

About $50 \%$ of the patients already had a history of metastatic disease or active disease outside the treatment area at the time of randomization (Table 3). The majority of the patients ( 227 of 306 or $74 \%$ ) showed progression outside the treatment area during follow-up (Table 6). This had a major impact on survival and explains why the higher local CR rate with HT is not reflected in a survival advantage. Only 4 of the CR patients died without evidence of progressive disease elsewhere, 2 of them in continuous local CR and 2 after a local relapse. Of the CR patients, 64 died with distant progressive disease, 56 of them still in local $\mathrm{CR}$. Of the patients who did not reach a CR, 112 have died, almost all of them (91\%) with progressive disease outside the treatment area.

The survival experience is summarised in Fig. 3 and Table 6, indicating a median survival of approximately 18 months irrespective of treatment received. The 2-year actuarial survival rate for all patients was approximately $40 \%$. Between-trial differences reflect the respective protocol eligibility requirements, as well as differing disease status at entry; for example, the MRC BrR trial contains a high proportion of patients with metastatic disease or a history of metastatic disease at randomization.

\section{Side effects and toxicity}

Overall, both treatments were well-tolerated, with no patients refusing to complete the prescribed radiation, but a small number of patients had their HT treatments terminated early because of pain. In addition, two patients had HT halled because of the discovery of pleural effusions that made it impossible for them to lie flat.

Because of the different scales used, a detailed comparative analysis of the degrees of toxicity experienced across all trials is not possible, but the common acute and

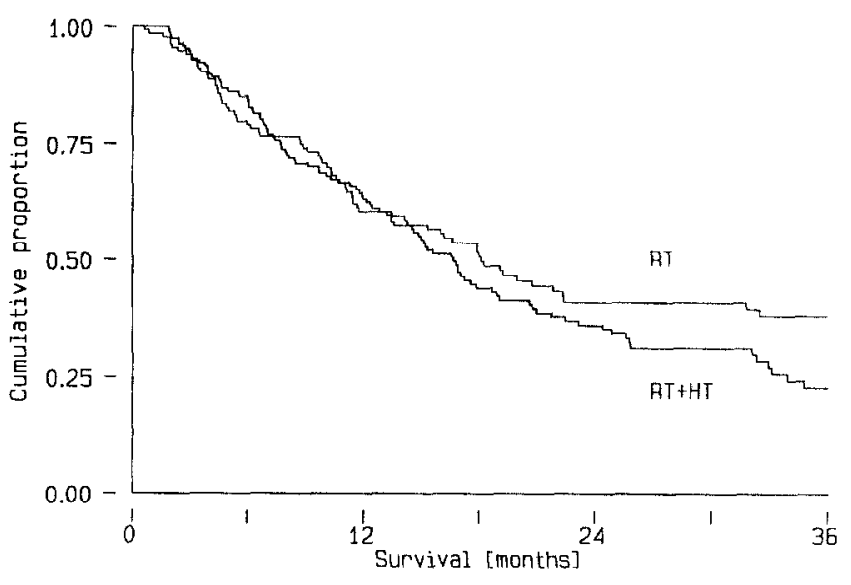

Fig. 3. Overall survival by arm; pooled 
late side effects of therapy are summarized in Table 7 by treatments received, for those patients for whom this information is available.

In terms of acute reactions, there is little difference in erythema and desquamation between treatments but, as expected, more blistering occurred with the addition of HT $(11 \%)$ as compared to RT alone (2\%). This excess is noted in all trials except MRC BrI, where no blistering occurred in cither treatment arm. Similarly, acute effects of $\mathrm{HT}$ were $7 \%$ ulceration and $7 \%$ necrosis in the combined arm, compared with $2 \%$ and $1 \%$, respectively in the RT-only arm. These were greatest in the MRC BrR trial, where $10 \%$ of patients receiving HT suffcred some carly necrosis. In general, the acute effects of HT treatment tended to occur in areas of reduced sensitivity and healed with conservative treatment, with little impact on patient well-being.

Severe late reactions occurred: 1 each of bone necrosis, bone fracture, and brachial plexus lesion, all in the combined arm of the ESHO trial. The late effects of pigmen- tation, telangiectasia, and fibrosis show very little variation between treatments.

Thus, HT, as delivered in these trials, was well tolerated and did not significantly add to either the clinically relevant acute or long-term toxicity over irradiation alone, even in those patients who had received prior radical $\mathrm{RT}$.

\section{DISCUSSION}

The trials presented in this paper result from a multicenter international collaboration, and the analysis has demonstrated a statistically significant benefit from the use of HT, in addition to radiation, in superficial breast cancer.

In view of the need for quality assurance for HT treatment highlighted in previous trials (23), an effort was made to ensure that only tumors that could be heated satisfactorily would be entered into the trials. For this reason, quality assurance guidelines based on general experience

Table 7 . Summary of recorded treatment-related toxicity by trial and treatment

\begin{tabular}{|c|c|c|c|c|c|c|c|c|c|c|c|c|}
\hline & \multicolumn{2}{|r|}{ DHG } & \multicolumn{2}{|c|}{ MRC BrI } & \multicolumn{2}{|c|}{ MRC BrR } & \multicolumn{2}{|r|}{ ESHO } & \multicolumn{2}{|r|}{ PMH } & \multicolumn{2}{|c|}{ TOTAL } \\
\hline & $\mathrm{RT}$ & $\mathrm{RT}+\mathrm{HT}$ & RT & $\mathrm{RT}+\mathrm{HT}$ & RT & $\mathrm{RT}+\mathrm{HT}$ & RT & $\mathrm{RT}+\mathrm{HT}$ & RT & $\mathrm{RT}+\mathrm{HT}$ & RT & $\mathrm{RT}+\mathrm{HT}$ \\
\hline \multicolumn{13}{|c|}{ Erythema (mild/mod) } \\
\hline No & 11 & 9 & 7 & 11 & 21 & 46 & 11 & 10 & 7 & 5 & 57 & 81 \\
\hline Yes & 2 & 7 & 5 & 6 & 33 & 42 & 16 & 15 & 9 & 12 & $\begin{array}{l}65 \\
53 \%\end{array}$ & $\begin{array}{l}82 \\
50 \%\end{array}$ \\
\hline \multicolumn{13}{|c|}{$\begin{array}{l}\text { Erythema } \\
\text { (severe/desquamation) }\end{array}$} \\
\hline No & 5 & 8 & 12 & 15 & 48 & 77 & 18 & 17 & 10 & 9 & 93 & 126 \\
\hline Yes & 8 & 8 & 0 & 2 & 6 & 11 & 9 & 8 & 6 & 8 & $\begin{array}{l}29 \\
24 \%\end{array}$ & $\begin{array}{l}37 \\
23 \%\end{array}$ \\
\hline \multicolumn{13}{|l|}{ Blister } \\
\hline No & 13 & 15 & 12 & 17 & 53 & 82 & 27 & 20 & 15 & 13 & 120 & 147 \\
\hline Yes & 0 & 3 & 0 & 0 & 1 & 6 & 0 & 6 & 1 & 4 & $\begin{array}{l}2 \\
2 \%\end{array}$ & $\begin{array}{l}19 \\
11 \%\end{array}$ \\
\hline \multicolumn{13}{|c|}{ Ulceration } \\
\hline No & 13 & 16 & 12 & 16 & 52 & 85 & 27 & 22 & 16 & 16 & 119 & 155 \\
\hline Yes & 0 & 2 & 0 & 1 & 2 & 3 & 0 & 4 & 0 & 1 & $\begin{array}{l}3 \\
2 \%\end{array}$ & $\begin{array}{l}11 \\
7 \%\end{array}$ \\
\hline \multicolumn{13}{|c|}{ Necrosis } \\
\hline No & 13 & 17 & 12 & 16 & 53 & 78 & 27 & 26 & 16 & 17 & 121 & 154 \\
\hline Yes & 0 & 1 & 0 & 1 & 1 & 10 & 0 & 0 & 0 & 0 & $1 \%$ & $\begin{array}{l}12 \\
7 \%\end{array}$ \\
\hline \multicolumn{13}{|c|}{ Fibrosis } \\
\hline No & $6^{*}$ & $5^{*}$ & 4 & 7 & $24 *$ & $24^{*}$ & $3^{*}$ & $9^{*}$ & 9 & 10 & 46 & 55 \\
\hline Yes & 4 & 4 & 8 & 10 & 14 & 35 & 4 & 3 & 7 & 7 & $\begin{array}{l}37 \\
45 \%\end{array}$ & $\begin{array}{l}59 \\
52 \%\end{array}$ \\
\hline \multicolumn{13}{|c|}{ Telangiectasia } \\
\hline $\begin{array}{l}\text { No } \\
\text { Yes }\end{array}$ & $8^{*}$ & $\begin{array}{l}9^{*} \\
0\end{array}$ & $\begin{array}{l}8 \\
4\end{array}$ & 10 & $27^{*}$ & $39^{*}$ & $6^{*}$ & $10^{*}$ & - & - & $\begin{array}{l}49 \\
18\end{array}$ & $\begin{array}{l}68 \\
29\end{array}$ \\
\hline & & & 4 & t & 11 & 20 & 1 & 2 & & & $27 \%$ & $30 \%$ \\
\hline \multicolumn{13}{|c|}{ Pigmentation } \\
\hline $\begin{array}{l}\text { No } \\
\text { Yes }\end{array}$ & $\begin{array}{l}4^{*} \\
6\end{array}$ & $\begin{array}{l}3^{*} \\
6\end{array}$ & $\begin{array}{l}9 \\
3\end{array}$ & $\begin{array}{r}14 \\
3\end{array}$ & $\begin{array}{l}22^{*} \\
16\end{array}$ & $\begin{array}{l}29 * \\
30\end{array}$ & $1^{*}$ & $\begin{array}{l}4^{*} \\
8\end{array}$ & $\begin{array}{r}11 \\
5\end{array}$ & $\begin{array}{r}12 \\
5\end{array}$ & $\begin{array}{l}47 \\
36\end{array}$ & $\begin{array}{l}62 \\
52\end{array}$ \\
\hline & & & & & & & & & & & $43 \%$ & $46 \%$ \\
\hline
\end{tabular}

* Confined to patients with at least 1 year of follow-up.

- Not recorded. 
and consensus within the HT communities in Europe and North America $(8,12)$ were adopted. In addition, quality assurance programs in some institutes were assessed during site visits carried out under the auspices of ESHO (16).

Superficial breast cancer was chosen for the trials because, even within the limitations of available HT equipment, it was felt by the individual trial groups that it was feasible to heat the relatively shallow lesions adequately and to obtain satisfactory measurements of the temperature distribution at several locations within the treated field.

The combined therapy was well tolerated and did not result in major toxicity. There were, however, differences in outcome between the individual trials with two, MRC $\mathrm{BrR}$ and ESHO, illustrating an advantage for HT. In the DHG trial, there was no apparent difference between the treatments and MRC BrI and PMH indicated a small advantage for RT alone. Note, however, that all of the $95 \%$ CIs for the odds ratios (OR) from the five trials are not inconsistent with a substantial benefit from HT (Fig. 1).

Overall survival did not differ markedly between the two treatment arms, although the pooled data suggest that the group receiving additional $\mathrm{HT}$ has a marginally infe rior survival, as shown in Fig. 2. This may be caused by lesion size, which has been shown to be of prognostic value for overall survival (4), and was larger in the combined treatment arm.

We have shown that size and depth of lesions, distant metastatic disease, and RT dose are important factors that affect $C R$ rate. The patients in these trials are heterogeneous in these respects and this accounts, in part, for the variable CR rates between the trials. However, following adjustment for these factors, there remains a statistically significant difference in CR rate in favor of HT. The numbers of patients in the individual trials are small and any inferences drawn from the inter-trial differences may, as a consequence, be unreliable. Nevertheless, these differences do raise some interesting questions with regard to the possible differences in efficacy of varying RT and HT regimens. which are testable hypotheses for future trials.

There are differences within the five trials that may be important. All the MRC BrI patients, approximately two thirds of the DHG patients, and a smaller proportion in the MRC BrR and PMH trials, received radical RT. The MRC BrI patients had primary breast cancer that was deemed inoperable because of disease extent, and these lesions were probably more difficult to heat adequately. The depths of these tumors were estimated clinically and it is possible that this may have been underestimated. These patients, therefore, may not have complied with the guidelines for HT. The lesion sizes of the DHG patients were smaller, and we would expect all such patients to achieve a higher $\mathrm{CR}$ rate. The treatments delivered also varied between trials. Estimates of the equivalent radiation doses showed considerable differences between the palliative schedules, although the radical doses were less variable. Bedwinek et al. (3) have defined 'adequate' RT doses for recurrent tumors of different sizes and depths. However, tumors in previously irradiated areas cannot be adequately treated by RT alone because of the effect on normal tissues, and because the hypoxia induced by previous $R T$ renders the tumor less sensitive to the effects of radiation. We believe that it is important to give the maximum tolerated dose of radiation, even in those patients who have received previous radiation. to achieve the highest possible CR rates. There was significant variation in the prescription of heat treatments in the different trials, hence, making the establishment of a hcat-response relationship difficult. It would appear, however, that the PMH trial had the lowest number and duration of heat treatments, with the lowest CR rate achieved for the combined treatmont arm. A number of possibilities may account for this outcome, such as the small number of patients, variation in clinical characteristics, and low RT dose, but the possibility that this may have been influenced by the heat treatments cannot be excluded.

The combined results reported here have, we suggest, confirmed the view that the role of HT in the treatment of breast cancer is as an adjunct to a palliative dose of RT in patients with tumor recurrence following a radical course of treatment.

These trials do not establish the beneficial use of HT for patients who are able to receive a full dose of radiation, but the numbers of patients treated radically in these trials is small and the apparent lack of success with the addition of HT may be explicable by other factors, as already discussed. Biologically, there is no reason why HT should not be of benefit in the radical situation, and future trials should look at these patients in greater numbers.

The randomized trial reported by Overgaard et al. (21) in patients with recurrent or metastatic malignant melanoma treated hy RT with or without HT, has shown CR rates of $46 \%$ for the combined arm and $28 \%$ for the radiation-only arm, which are similar to our own. This was a small trial based on only 71 patients with 134 lesions, and the form of analysis used leads to some doubt as to how reliable these estimates of CR really are (19). However, both this trial and our own, with the CR rate at 2 years of $59 \%$ for irradiation plus HT vs. $41 \%$ for irradiation alone, is in keeping with other Phase III randomized trials. Following the results of our trials, we could recommend the consideration of HT for patients with recurrent breast cancer to be retreated with irradiation. We hope that these results will encourage the use of HT in clinical practice and, also, further study into its use in other tumor types, as well as the best scheduling of HT and radiation. Further research is also required to assess the benefit of HT on those patients for whom radical radiation is planned.

We would emphasize that, without the international collaboration, each of these five trials would have been too small to contribute meaningful data on the role of HT in superficial breast cancer. This must have important implications for the planning of future trials. 


\section{ACKNOWLEDGEMENTS}

\section{Medical Research Council Trials}

We acknowledge the financial support of the hyperthermia program at the Cyclotron Unit provided by the Medical Research Council (MRC; United Kingdom); the expertise of M. V. Prior, G. R. Forse, J. Khudhail, and Y. Robinson in administering hyperthermia; the contributions to assessment made by J. Flanders and F. Paice; the secretarial support of V. Jackson and V. Ellen; and computer support from L. Jenkin.

\section{Dutch Hyperthermia Group and European Society Hyperthermic Oncology Trials}

We acknowledge the contributions of P. J. van Assendelft in data management, of all involved in the administration of the hyperthermia treatments, and of J. Overgaard for contribution to protocol design for the European Society Hyperthermic Oncology (ESHO) trial.

We also acknowledge the financial support of The Netherlands Cancer Foundation "Koningin Wilhelmina Fonds" (several grants for the development of clinical hyperthermia application), the Willem Kröger Stichting, the Maurits and Anna de Kock Stichting, and the Stichting Bevordering Volkskracht, for hyperthermia equipment.

The contributions of J. D. P. van Dijk, C. J. Schneider and G. Lamaitre of the Dept of Radiotherapy, Academic Medical Center, Amsterdam, in carrying out the hyperthermia QA site visit program under the auspices of the ESHO Technical Committee and with financial support of the Concerted Action program (COMAC BME contracts M4*/0204/B and 0306/B) within the European Commission's 4th Medical and Health Research Programme are also acknowledged.

The following clinicians entered patients into the Dutch Hyperthermia Group (DHG) and ESHO trials: G. van Tienhoven, M. C. C. M. Hulshof, L. E. C. M. Blank, J. G. J. Letschert, F. Oldenburger and A. L. J. SchusterUitterhoeve, Academic Medical Center, Amsterdam, The Netherlands (41); A. D. Treurniet-Donker, W. A. M. Mellink, P. C. M. Koper, B. A. Reichgelt, P. A. Helle, A. Slot, A. J. Wijnmaalen, J. J. Seldenrath, P. L. A. van den Ende and P. J. C. M. Nowak, Dr. Daniel den Hoed Cancer Center, Rotterdam, The Netherlands (27); M. Amichetti and
C. Graiff, Oncology Center, San Chiara Hospital, Trento, Italy (8); J. Fijuth, Institute of Oncology, Warsaw, Poland (7); P. Hoffman and H. K. Wijrdeman, University Hospital, Utrecht, The Netherlands (3); P. F. Steindorfer and W. Amann, University Hospital Graz, Austria (3); G. Arcangeli, San Maria Goretti Hospital, Latina, Italy (2); and M. Treitz, Kliniken der Stadt Saarbrücken, Germany (1).

The following clinicians entered patients into the MRC trials: C. Vernon, H. Lambert, C. Mackenzie, J. Waxman, J. Stewart, A. Munro, K. Sikora, P. Price, A. Epenetos, Ilammersmith Hospital, London (87); J. Maher, M. Saunders, Mount Vernon Hospital, Northwood (18); C. Coulter, M. Spittle, A. Cassoni, Middlesex Hospital, London (18); A. Jones, C. Alcock, D. Cole, Churchill Hospital, Oxford (9); C. Harmer, J. Yarnold, Royal Marsden Hospital, London (7); J. Dobbs, King's College Hospital, London (6); M. Ghilchick, St. Mary's Hospital, London (6); A. Timothy, St. Thomas' Hospital, London (4); D. Tong, Guy's Hospital, London (4); I. Kunkler, Weston Park Hospital, Sheffield (3); D. Pickering, Maidstone Hospital, Maidstone, Kent (2); J. Tobias, University College Hospital, London (2); P. Plowman, St Bartholomew's Hospital (2), London; R. Beaney, J. Mould, Queen Elizabeth Hospital, Birmingham (2); N. Bleehen, Addenbrooke's Hospital, Cambridge (2); C. Keen, T. Maughan, University Hospital of Wales, Cardiff (2); H. Smedley, Kent and Canterbury Hospital, Canterbury, Kent (1); B. Southcott, Charing Cross Hospital, London (1); P. Murray, Essex County Hospital, Colchester (1); A. Hong, Royal Devon and Exeter Hospital, Exeter (1); A. Folkes, Royal Surrey County Hospital, Guildford (1); V. Svoboda, St Mary's Hospital, Portsmouth (1); and H. Hope-Stone, Royal London Hospital, London (1).

\section{Princess Margaret Hospital Trial}

We acknowledge the clinical support of W. Levin, L. Manchul, P. Kirkbride, G. Rawlings, and L. Yeoh; the scientific support of R. P. Hill and J. W. Hunt; the technical support of B. Cooper, D. Newcombe, and W. Taylor; and the statistical support of E. Rawlinson and M. Pintilie. The financial contributions of the Princess Margaret Hospital Trust Foundation, the Canadian Breast Cancer Foundation, and the Ontario Cancer Treatment and Research Foundation are also acknowledged.

\section{REFERENCES}

1. Aberizk, W. J.; Silver, B.; Henderson, I. C.; Cady, B.; Harris, J. R. The use of radiotherapy for treatment of locoregional recurrence of breast carcinoma after mastectomy. Cancer 58:1214-1218; 1986

2. Altman, D. G. Practical statistics for medical research. London: Chapman and Hall; 1991.

3. Bedwinek, J. M.; Fineberg, B.; Lee, J.; Ocwieza, M. Analysis of failures following local treatment of isolated localregional recurrence of breast cancer. Int. J. Radiat. Oncol. Biol. Phys. 7:581-585; 1981.

4. Bedwinek, J. M.; Lee, J.; Fineberg, B.; Ocwieza, M. Prog- nostic indicators in patients with isolated local-regional recurrence of breast cancer. Cancer 47:2232-2235; 1981.

5. Coley, W. C. The treatment of malignant tumours by repeated inoculations of erysipelas; with a report of 10 original cases. Am. J. Med. Sci. 105:486-511; 1893.

6. COMPACT Steering Committee. Improving the quality of clinical trials in cancer. Br. J. Cancer 63:412-415; 1991.

7. Cox, R. S.; Kapp, D. S. Correlation of thermal parameters with outcome in combined radiation therapy-hyperthermia trials. Int. J. Hyperthermia 8:719-732; 1992.

8. Dewhirst, M. W.; Phillips, T. L.; Samulski, T. V.; Staufter, 
P.; et al. RTOG quality assurance guidelines for clinical trials using hyperthermia. Int. J. Radiat. Oncol. Biol. Phys. 18:1249-1259; 1990.

9. Egawa, S.; Tsukiyama, I.; Watanabe, S.; Ohno, Y.; Morita, K.; Tomingawa, S.; Onoyama, Y.; Hashimoto, S.; Yanagawa, S.; Uehara, S.; Abe, M.; Mochizuki, S.; Sugiyama, A.; Inoue, T. A randomised clinical trial of hyperthermia and radiation vs. radiation alone for superficially located cancers. J. Jpn. Soc. Ther. Radiol. Oncol. 1:135-140; 1989.

10. Field, S. B.; Hand, J. W., eds. An introduction to the practical aspects of clinical hyperthermia. London: Taylor \& Francis; 1990

11. González González, D.; van Dijk, J. D. P.; Blank, L. E. C. M. Chestwall recurrences of breast cancer: Results of combined treatment with radiation and hyperthermia. Radiother. Oncol. 12:95-103; 1988.

12. Hand, I. W.; I agendijk, J. I. W.; Anderson, I. B.; Bolomey, J. C. Quality assurance guidelines for ESHO protocols. Int. J. Hyperthermia 5:421-428; 1989.

13. International Union Against Cancer. TNM classification of malignant tumours, 4th ed. Berlin: Springer-Verlag; 1992.

14. Kapp, D. S.; Petersen, I. A.; Cox, R. S.; Hahn, G. M.; Fessenden, P.; Prionas, S. D.; Lee, E. R.; Meyer, J. L.; Samulski. T. V.; Bagshaw, M. A. Two or six hyperthermia treatments as an adjunct to radiation therapy yield similar tumour responses: Results of a randomised trial. Int. J. Radiat. Oncol. Biol. Phys. 19:1481 1495; 1990.

15. Kjellen, E.; Lindholm, C.-E.; Nilsson, P. Radiotherapy in combination with hyperthermia in recurrent or metastatic mammary carcinomas. In: Sugahara, T.; Saito, M., eds. Hyperthermic Oncology, Vol. 1. London and New York: Taylor \& Francis; 1988:426-429.

16. Lamaitre, G.; Postma, A. J.; van Dijk, J. D. P. In: The COMAC-BME site visit program for superficial heating devices: Preliminary results (Abstr.). Book of abstracts. 13th ESHO conference. Brussels: 1993.

17. Lewis, J. A.; Machin, D. Intention to treat-who should use ITT. Br. J. Cancer 68:647-650; 1994.

18. Machin, D.; Campbell, M. J. Statistical tables for the design of clinical trials. Oxford: Blackwell; 1987.

19. Machin, D.; Parmar, M. K. B. Hyperthermia in cancer treatment. Lancet 345:1635-1636; 1995.

20. Muiller. C. Eine neue behandlungsmethode bösartiger geschwiilste. Munch. Med. Wochenschr 28:1490-1493; 1910.

21. Overgaard, J.; González González, D.; Hulshof, M. C. C. M.; Arcangeli, G.; Dahl, O.; Mella, O.; Bentzen, S. M., for the European Society of Hyperthermic Oncology. Randomised trial of hyperthermia as adjuvant to radiotherapy for recurrent or metastatic malignant melanoma. Lancet 345:540-543; 1995.
22. Parmar, M. K. B.; Machin, D. Survival analysis: A practical approach. Chichester, UK: Wiley: 1995.

23. Perez, C. A.; Gillespie, B.; Pajak, T.; Hornback. N. B.; Emami, B.; Rubin, P. Quality assurance problems in clinical hyperthermia and their impact on therapeutic outcome: a report by the Radiation Therapy Oncology Group. Int. J. Radiat. Oncol. Biol. Phys. 16:551-558; 1989.

24. Perez, C. A.; Kuske, R. R.; Emami, B,; Fineberg, B. Irradiation alone or combined with hyperthermia in the treatment of recurrent carcinoma of the breast in the chest wall: A nonrandomized comparison. Int. J. Hyperther. 2:179-187; 1986.

25. Perez, C. A.; Pajak, T.; Emami, B.; Hornback, N. B.; Tupchong, L.; Rubin, P. Randomized Phase III study comparing irradiation and hyperthermia with irradiation alone in superficial measurable tumors. Am. J. Clin. Oncol. (CCT) 14:133$141 ; 1991$.

26. Schmidt, W. E. 7ur Röntganbehandlung trefliegander tumoren. Fortsor. Roengenstr. 14:134; 1909.

27. Scott, R. S.; Johnson, R. J. R.; Story, K. V.; Clay, L. Local hyperthermia in combination with definitive radiotherapy: Increased tumour clearance, reduced recurrence rate in extended follow-up. Int. J. Radiat. Oncol. Biol. Phys. 10:21 19$2123 ; 1984$.

28. Stadler, B.; Kogelnik, D. H. Local control and outcome of patients irradiated for isolated chest wall recurrences of breast cancer. Radiother. Oncol. 8:105-111; 1987.

29. Stata reference manual: release 3.1 , 6th ed. Santa Monica, CA; Stata Corporation. 1993

30. Steel, G. G., ed. Basic clinical radiobiology. Sevenoaks, UK: Edward Arnold; 1993

31. Valdagni, R.; Amichetti, M.; Pani, G. Radical radiation alone vs. radical radiation plus microwave hyperthcrmia for $\mathrm{N}_{3}$ (TNM-UICC) neck nodes: A prospective randomized clinical trial. Int. J. Radiat. Oncol. Biol. Phys. 15:13-24; 1988.

32. Valdagni, R.; Liu, F.-F.; Kapp, D. S. Important prognostic factors influencing outcome of combined radiation and hyperthermia. Int. J. Radial. Oncol. Biol. Phys. 15:959-972; 1988.

33. van der Zee, J.; Treurniet-Donker, A. D.; The, S. K.; Helle, P. A.; Seldenrath, J. J.; Meerwaldt, J. H.; Wijnmaalen, A. J.; van den Berg, A. P.; van Rhoon, G. C.; Broekmeyer-Reurink, M. P.; Reinhold, H. S. Low dose reirradiation in combination with hyperthermia: a palliative treatment for patients with breast cancer recurring in previously irradiated areas. Int. J. Radiat. Oncol. Biol. Phys. 15:1407-1413; 1988.

34. Westermark, F. Uber die Behandlung des Ulcerierenden Cervixcarcinoms mittels konstanter warme. Zbl. Gynakol. 22:1335-1339; 1898 .

35. WHO handbook for reporting results of cancer treatment. WHO Offset Publication No. 48. Geneva: WHO; 1979. 